\section{(2) OPEN ACCESS}

\title{
The increasing impact of cerebral amyloid angiopathy: essential new insights for clinical practice
}

\author{
Gargi Banerjee, ${ }^{1}$ Roxana Carare, ${ }^{2}$ Charlotte Cordonnier, ${ }^{3}$ Steven M Greenberg, ${ }^{4}$ \\ Julie A Schneider, ${ }^{5}$ Eric E Smith, ${ }^{6}$ Mark van Buchem, ${ }^{7}$ Jeroen van der Grond, ${ }^{7}$ \\ Marcel M Verbeek, ${ }^{8,9}$ David J Werring ${ }^{1}$
}

For numbered affiliations see end of article.

\section{Correspondence to}

Dr David J Werring, The National Hospital for Neurology and Neurosurgery, UCL Institute of Neurology, Queen Square, London WC1N 3BG, UK; d. werring@ucl.ac.uk

Received 1 March 2017 Revised 26 April 2017

Accepted 18 May 2017 Published Online First 26 August 2017

CrossMark

To cite: Banerjee $\mathrm{G}$, Carare R, Cordonnier C, et al. J Neurol Neurosurg Psychiatry 2017;88:982-994.

\section{ABSTRACT}

Cerebral amyloid angiopathy (CAA) has never been more relevant. The last 5 years have seen a rapid increase in publications and research in the field, with the development of new biomarkers for the disease, thanks to advances in MRI, amyloid positron emission tomography and cerebrospinal fluid biomarker analysis. The inadvertent development of CAA-like pathology in patients treated with amyloid-beta immunotherapy for Alzheimer's disease has highlighted the importance of establishing how and why CAA develops; without this information, the use of these treatments may be unnecessarily restricted. Our understanding of the clinical and radiological spectrum of CAA has continued to evolve, and there are new insights into the independent impact that CAA has on cognition in the context of ageing and intracerebral haemorrhage, as well as in Alzheimer's and other dementias. While the association between CAA and lobar intracerebral haemorrhage (with its high recurrence risk) is now well recognised, a number of management dilemmas remain, particularly when considering the use of antithrombotics, anticoagulants and statins. The Boston criteria for CAA, in use in one form or another for the last 20 years, are now being reviewed to reflect these new wide-ranging clinical and radiological findings. This review aims to provide a 5-year update on these recent advances, as well as a look towards future directions for CAA research and clinical practice.

\section{INTRODUCTION}

Cerebral amyloid angiopathy (CAA), a cerebral small vessel disease (SVD) characterised by the presence of amyloid-beta $(A \beta)$ protein within cortical and leptomeningeal blood vessel walls, ${ }^{1}$ is a condition of increasing clinical and mechanistic importance. Although recognised pathologically since the early 20th century, CAA had been sidelined until it was more firmly associated with lobar intracerebral haemorrhage (ICH) many years later. ${ }^{2}$ This, together with the use of blood-sensitive magnetic resonance sequences to visualise asymptomatic haemorrhagic events that far exceed those causing clinical symptoms, has expanded our understanding of what CAA is and its clinical significance. ${ }^{2-4}$ The last 5 years have seen ongoing progress in this area, thanks in part to the development of new technologies within the fields of magnetic resonance, amyloid positron emission tomography ligands and cerebrospinal fluid (CSF) biomarker analysis. ${ }^{4}$
Furthermore, CAA gained new relevance with the advent of anti-A $\beta$ immunotherapies for the treatment of Alzheimer's disease (AD), as a sizeable proportion of those treated went on to develop imaging features of CAA-related inflammation as an unintended consequence..$^{5}$ This, together with advances in our understanding of the impact of CAA on cognition, in the context of $\mathrm{ICH}$, ageing and $\mathrm{AD}$, has broadened the clinical spectrum of disease to which the contribution of CAA is recognised. The 5th International CAA Conference, held in Boston, Massachusetts in September 2016 (https://caaforum.org/event/5 th-international-caaconference-2016-boston-ma/), highlighted many of these developments, as well as a need to update the current diagnostic Boston criteria to better reflect these new wide-ranging clinical and radiological findings.

This review aims to provide a clinically oriented update on these recent advances, focusing on those in the last 5 years, since our last comprehensive review. ${ }^{3}$ Specifically, we will focus on newly identified biomarkers for CAA and their potential mechanistic implications, as well as the latest insights into the pathophysiology and causes of CAA. We will also report on the expanding spectrum of clinical presentations associated with CAA, before finally considering the ongoing management dilemmas that face physicians working in neurology, elderly care and stroke medicine, among others, when faced with this disease.

\section{BIOMARKERS ADVANCES AND MECHANISTIC INSIGHTS}

Insights from hereditary cerebral haemorrhage

with amyloidosis-Dutch type (HCHWA-D)

Establishing the natural history of sporadic CAA is difficult, in part due to the limited sensitivity of our current diagnostic criteria, ${ }^{67}$ and also due to the high prevalence of comorbid changes caused by ageing and other neurodegenerative disorders. Moreover, most of these clinical and radiological features are thought to occur relatively late in the disease process; given that any potential window for treatment is likely to be at earlier stages of the disease, this is likely to significantly limit their use as feasible biomarkers.

HCHWA-D is an autosomal dominant disease that predominantly occurs in a limited number of families in the villages of Katwijk and Scheveningen in the Netherlands. ${ }^{8}$ A point mutation 
(E693Q) of the amyloid precursor protein (APP) gene ${ }^{9}$ leads to extensive $A \beta$ deposition in the cortical and leptomeningeal arterioles and arteries. The underlying pathology of these $A \beta$ deposits is similar to that in sporadic CAA with minimal or no neurofibrillary pathology. ${ }^{8}$ Most importantly, mutation carriers develop symptoms (recurrent ICH and dementia ${ }^{10}$ ) relatively early in life, usually between the ages of 50 and 60 years. Therefore, using HCHWA-D as a model allows CAA-related changes to be studied with minimal confounding by comorbidities associated with ageing. This genetic condition also opens the possibility to find new disease markers, even in the presymptomatic phase.

Previous studies have shown that the characteristic radiological signs of sporadic CAA are mimicked in symptomatic HCHWA-D, namely numerous lobar microbleeds with or without cortical superficial siderosis (cSS). ${ }^{311} 12$ In presymptomatic HCHWA-D, haemorrhagic changes are present, but more subtle; in recent studies, none or only one of the 'classical' signs (lobar microbleeds, macrohaemorrhage, cSS or convexity subarachnoid haemorrhage, cSAH) were present. ${ }^{13}$ However, other disease markers such as white matter hyperintensities (WMH) and cortical microinfarcts, which are ischaemic manifestations of $\mathrm{CAA},{ }^{3}$ were already prevalent among presymptomatic HCHWA-D subjects. ${ }^{13}$ This indicates that these disease manifestations are among the earliest markers of the hereditary form of CAA and precede ICH. In addition to explicit white matter changes, the grey matter is also specifically but subtly affected; recent data clearly showed that both patients with CAA and HCHWA-D demonstrate similar patterns of cortical thinning, suggesting that vascular $A \beta$ is an independent contributor to cortical atrophy (figure 1). ${ }^{14}$

Vascular reactivity is measured by blood-oxygen level-dependent (BOLD) amplitude, time to response and time to return to baseline after visual stimulation. Cerebrovascular dysfunction is intrinsically associated with CAA disease pathology by $\mathrm{A} \beta$ deposition in the vessel wall, resulting in impaired vascular reactivity in symptomatic patients with CAA. ${ }^{15}$ Recently it was shown that similar changes are also present in symptomatic HCHWA-D. ${ }^{16}$ Determination of vascular reactivity in symptomatic and presymptomatic HCHWA-D showed that in both groups vascular reactivity was significantly decreased in the occipital lobe. ${ }^{16}$ Although this effect was far more pronounced in the symptomatic group, raising the possibility that these effects may be influenced by the presence of occipital macrohaemorrhage, the finding of reduced vascular reactivity even in presymptomatic patients with HCHWA-D suggests it as an early step in CAA pathogenesis.

Both the haemorrhagic and haemodynamic cerebral changes are secondary effects of $A \beta$ deposition in the cerebrovascular vessel wall ${ }^{17}$; a key future goal is to determine the level of $A \beta$ deposition in the vessel wall itself. Measurement of $A \beta$ species in the CSF shows reductions in both $A \beta 40$ and $A \beta 42$ in presymptomatic as well as symptomatic patients with HCHWA-D. ${ }^{18}$ These findings point to $A ß$ deposition as another marker of the earliest phase of CAA-related pathology, occurring before clinical or radiological findings appear.

In summary HCHWA-D appears to be an excellent model to study important aspects of CAA, particularly presymptomatic brain imaging changes, which are much more difficult to investigate in sporadic CAA. With further biomarker development, HCHWA-D might also have promise for testing potential new disease-modifying therapies with potential relevance for sporadic CAA.
Related developments in sporadic CAA

Imaging

Neuroimaging remains a central component to the diagnosis of CAA, with a focus on the presence of the haemorrhagic manifestations of the disease: lobar macrohaemorrhage, strictly lobar microbleeds and cSS. ${ }^{6}$ The last 5 years have seen increased understanding of these markers, as well as the emergence of new potential structural and functional imaging markers for CAA, all of which may be of both diagnostic and mechanistic relevance. Some notable recent advances are summarised here (table 1). ${ }^{19-30}$

While multiple lobar ICH remains the strongest indicator for CAA, they are a late feature of the disease and may not be a practical outcome marker for clinical trials. ${ }^{31}$ The association between cSS and CAA is now well recognised, reflected by its inclusion in the modified Boston criteria. ${ }^{7}$ Clinically, cSS is associated with transient focal neurological episodes (TFNE) ${ }^{32}$ and an increased risk of $\mathrm{ICH},{ }^{33-35}$ including early recurrent $\mathrm{ICH} .{ }^{36}$ There is also increasing evidence that cSS is associated with cognitive impairment, although it is not clear whether this is because cSS is a marker of severe CAA or because it has direct and independent effects on cognition. ${ }^{37-45}$ The other haemorrhagic marker of CAA, the presence of strictly lobar microbleeds, remains central to diagnosis. However, recent work reviewing diagnostic accuracy of using strictly lobar microbleeds alone found that while they were strongly predictive of CAA in a hospital cohort, this was not the case in a healthy community population. ${ }^{46}$ This has highlighted the importance of identifying new imaging markers for CAA that can further improve the specificity and sensitivity of diagnosis, ${ }^{314}$ particularly outside ICH cohorts.

In the last 5 years new structural and functional imaging markers for CAA have emerged. As highlighted in a recent review, ${ }^{31}$ identifying new markers that could be used in therapeutic clinical trials is an urgent priority for CAA. Establishing CAA severity using neuroimaging also remains a challenge; a composite score has been proposed, ${ }^{48}$ which aims to estimate the overall pathological 'burden' of CAA in a given patient by combining key imaging markers of CAA, with some preliminary pathological verification of the concept. Evaluating this score against meaningful clinical outcomes will be essential for establishing whether it adds to the predictive value of individual markers or has practical application in clinical practice or future trials.

\section{Body fluid biomarkers in sporadic CAA}

Since CAA may arise due to the impaired clearance of $A \beta$ from interstitial cerebral fluid, CSF should contain biomarkers that reflect this process. A key factor in understanding the significance of the biomarkers in CSF will be to identify exactly the pathways for clearance of peptides from the interstitial fluid into the CSF.

It has been demonstrated that CAA-affected vessels, unlike senile plaques, contain significant $A \beta 40$ in addition to $A \beta 42,{ }^{49}$ which is abundantly found in senile plaques. This specific pattern of $A \beta 40 / 42$ deposition in CAA is reflected by decreased levels of both $A \beta 40$ and $A \beta 42$ peptides in CSF obtained from patients with CAA, diagnosed according to the Boston criteria, ${ }^{50}$ a finding replicated by other groups. ${ }^{51}$ Similarly, decreased CSF $A \beta 40$ and $A \beta 42$ concentrations were observed in patients with isolated cSS. ${ }^{52} \mathrm{~A}$ rare variant of CAA is CAA-related inflammation (CAA-ri), also known as A $\beta$-related angiitis. Patients with this condition suffer from acute or subacute neurological impairment, often including headache, encephalopathy, behavioural changes, seizures and focal neurological deficits. During the 

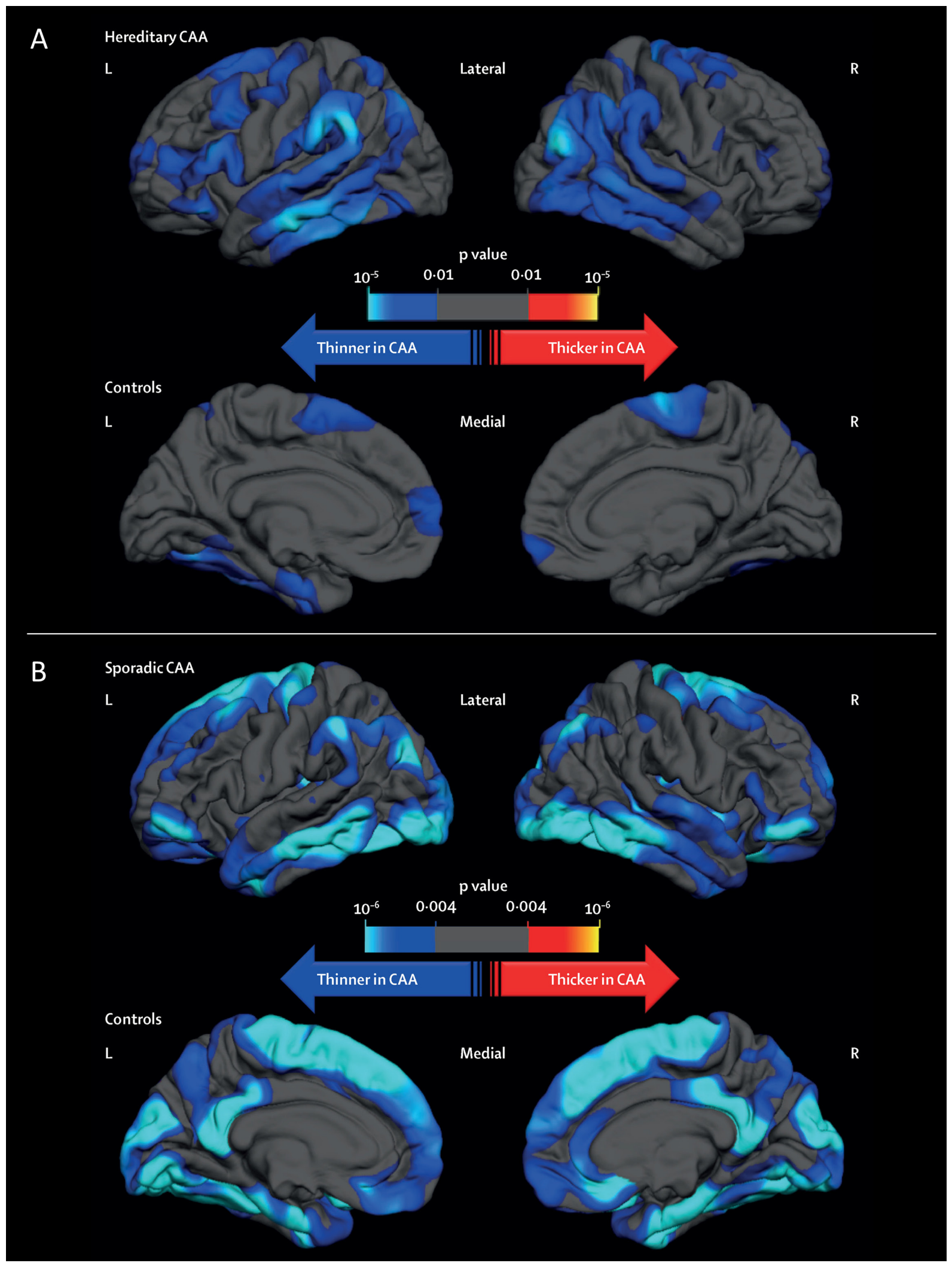

Figure 1 Differences in cortical thickness between patients with (A) hereditary cerebral haemorrhage with amyloidosis-Dutch type and (B) sporadic cerebral amyloid angiopathy, and their respective age-matched controls. A general linear model was computed to schematically explore the regional differences in cortical thickness between patients with (A) HCHWA-D and healthy controls and (B) sporadic CAA and healthy controls, after adjusting for age and sex. Topographic surface maps were generated using a threshold of $\mathrm{p}<0.01$ (with false discovery rate correction for multiple comparisons). The resulting maps show the statistically significant regional differences in cortical thickness. CAA, cerebral amyloid angiopathy; HCHWA-D, hereditary cerebral haemorrhage with amyloidosis-Dutch type; L, left; R, right. These panels have been reproduced without modification from ${ }^{14}$ (DOI: 10.1016/S14744422(16)30030-8), under the terms of the Creative Commons Attribution-NonCommercial-No Derivatives License (CC BY NC ND; https://creativecommons. org/licenses/by-nc-nd/4.0/legalcode). 
Table 1 Summary of potential new structural and functional imaging markers for CAA

\begin{tabular}{|c|c|c|}
\hline Imaging marker & Evidence of potential as a biomarker in CAA & Limitations \\
\hline $\begin{array}{l}\text { MRI visible perivascular } \\
\text { spaces in the centrum } \\
\text { semiovale (CSO-PVS) }\end{array}$ & $\begin{array}{l}\text { Severe or high-grade CSO-PVS commonly observed in CAA }{ }^{19-22} \\
\text { Pilot data show that, in those with CAA, CSO-PVS severity is associated with A } \beta \\
\text { burden (as measured by PiB) }\end{array}$ & $\begin{array}{l}\text { Non-specific (age-related); present in a number of } \\
\text { other conditions }{ }^{24}\end{array}$ \\
\hline Visual functional MRI & $\begin{array}{l}\text { Patients with CAA have abnormal BOLD responses to a visual stimulus (alternating } \\
\text { checkerboard), with reduced response amplitude and prolonged time both to peak } \\
\text { and to baseline } \mathrm{e}^{1525} \\
\text { Those with CAA show a decline in BOLD amplitude that is detectable at } 1 \text { year; } \\
\text { longitudinal difference in BOLD amplitudes was significantly lower in CAA } \\
\text { compared with controls }{ }^{26} \\
\text { Potentially of interest as a surrogate marker of vascular health in clinical trials }\end{array}$ & $\begin{array}{l}\text { Clinical implications of this remain unclear; due to } \\
\text { technical factors at this stage, this is predominantly } \\
\text { a research tool limited to academic medical centres }\end{array}$ \\
\hline Network measures & $\begin{array}{l}\text { Lower global efficiency of brain network in those with CAA; occipital, parietal and } \\
\text { posterior temporal lobes most affected } \\
\text { Reduced efficiency correlated with } A \beta \text { burden (as measured by PiB) and impaired } \\
\text { executive function and processing speed } \\
\text { Glo3 } \\
\text { GAal andiciency shows a longitudinal decline with time (1.3years) in those with } \\
\text { CAssociated with deteriorating executive function }{ }^{104}\end{array}$ & $\begin{array}{l}\text { Difficult to differentiate between network effects of } \\
\text { parenchymal } A \beta \text { versus those due to vascular A } \beta \text { in } \\
\text { sporadic CAA } \\
\text { Mainly a research tool limited to academic medical } \\
\text { centres }\end{array}$ \\
\hline $\begin{array}{l}\text { Amyloid PET imaging using } \\
{\left[{ }^{11} \mathrm{C}\right] \text { PiB-PET and }\left[{ }^{18} \mathrm{~F}\right]} \\
\text { compounds }\end{array}$ & $\begin{array}{l}\text { In those with CAA, regions with high PiB retention area associated with } \\
\text { subsequent haemorrhage } \\
\text { Although PiB-PET may not reliably distinguish between patients and age-matched } \\
\text { controls, }{ }^{28} \text { early phase }(1-6 \mathrm{~min}) \text { uptake can do this } \mathrm{s}^{29} \\
\text { The occipital/posterior cingulate ratio of PiB uptake is different for those with CAA } \\
\text { versus those with } \mathrm{AD}^{29} \\
\text { PiB-PET and }\left[{ }^{18} \mathrm{~F}\right] \text { florbetapir binding is able to distinguish between CAA- } \\
\text { associated ICH and hypertension-associated ICH }{ }^{30}\end{array}$ & $\begin{array}{l}\text { Amyloid PET unable to differentiate between } \\
\text { vascular and parenchymal A } \beta \\
\text { Diagnostic accuracy for CAA seems limited } \\
\text { Few data on change over time in CAA }\end{array}$ \\
\hline
\end{tabular}

$\mathrm{A} \beta$, amyloid-beta; AD, Alzheimer's disease; BOLD, blood-oxygen level-dependent; CAA, cerebral amyloid angiopathy; ICH, intracerebral haemorrhage; PET, positron emission tomography; PiB, Pittsburgh B compound.

acute phase of CAA-ri, increased levels of anti-A $\beta$ autoantibodies can be found in the $\mathrm{CSF}^{53}$ as well as decreased $\mathrm{A} \beta 40$ and $\mathrm{A} \beta 42$ levels. ${ }^{54}$

In single case reports of CAA caused by the Dutch-type $A \beta$ E22Q mutation and the Iowa-type A $\beta$ D23N mutation, similarly decreased levels of $A \beta 40$ and $A \beta 42$ peptides were found in $\mathrm{CSF}^{50}$; the results of larger studies suggest that these peptides might be promising preclinical markers of CAA, as discussed in the preceding section on HCHWA-D. ${ }^{18}$ Decreasing CSF A $\beta 40$ concentrations in these patients were associated with higher lobar microbleed count, increasing WMH volume and presence of cSS, and in addition were visible prior to the abnormalities present on neuroimaging.

As expected, levels of both total and phosphorylated tau protein are not specifically related to CAA and were marginally elevated in CSF from patients with CAA compared with controls, but were substantially lower than in patients with AD..$^{505154}$ Total tau protein levels are increased in CAA-ri, but both normal and increased levels of phosphorylated tau proteins have been described. ${ }^{515354}$ These minor elevations in CSF tau protein levels are probably attributable to a low level of concomitant AD pathology (neurofibrillary tangles) in patients with CAA. In contrast to the observations in sporadic CAA, both CSF total tau and phosphorylated tau concentrations were decreased in symptomatic, but not in presymptomatic patients with HCHWA-D compared with controls, although the difference in total tau disappeared after correction for age. ${ }^{18}$

Given the association of CAA with $\mathrm{AD}, \mathrm{CSF} A \beta$ protein levels have also been studied in correlation with the presence of CAA in patients with dementia, in which strictly lobar microbleeds on MRI (T2* or susceptibility weighted imaging, SWI) were used as the indicator of CAA. An independent correlation between decreased CSF A $\beta 42$ and the presence of cortical microbleeds was demonstrated in a heterogeneous cohort of patients with dementia. ${ }^{55}$ Patients with $\mathrm{AD}$ and with multiple microbleeds (defined as more than 8) also had lower CSF A 342 levels, compared with patients with $\mathrm{AD}$ without microbleeds, ${ }^{56}$ but such differences were not found for CSF A $\beta 40$ levels. ${ }^{56-58}$ This is in contrast with recent data that showed reductions in both CSF $\mathrm{A} \beta 40$ and $\mathrm{A} \beta 42$ in patients with $\mathrm{AD}$ and strictly lobar microbleeds compared with those with $\mathrm{AD}$ without microbleeds. ${ }^{59}$

By contrast with CSF biomarkers, studies on the association between blood levels of $A \beta$ proteins and the presence of CAA are rather limited. In patients with sporadic CAA, plasma $A \beta 40$, but not $\mathrm{A} \beta 42$, concentrations were associated with $\mathrm{WMH},{ }^{60}$ indicating that circulating $\mathrm{A} \beta$ peptides might be an indicator of cerebral microvascular damage. Moreover, in patients with multiple CAA-related $\mathrm{ICH}$, both plasma $\mathrm{A} \beta 42$ and $\mathrm{A} \beta 40$ concentrations were higher than in controls. ${ }^{61} \mathrm{~A}$ single study described that plasma $\mathrm{A} \beta 42$, but not $\mathrm{A} \beta 40$, levels were decreased in patients with HCHWA-D. ${ }^{10}$

Together, these data highlight the promise that body fluid biomarkers hold as potential preclinical markers for CAA. Further work, in particular in identifying viable plasma biomarkers, is needed.

\section{THE PATHOPHYSIOLOGY OF VASCULAR A $\beta$ DEPOSITION: AN UPDATE}

\section{Perivascular A $\beta$ clearance}

The deposition of $A \beta$ in the basement membranes of cerebral capillaries and arteries maps the intramural perivascular drainage pathways. ${ }^{62}{ }^{63}$ When physiological small volumes of $A \beta 40$ or other solutes are injected into the grey matter of experimental rodent brains, the $\mathrm{A} \beta 40$ enters basement membranes of capillaries and basement membranes surrounding smooth muscle cells 
of arteries within 5 min of intracerebral injection, mirroring the deposition of $\mathrm{A} \beta$ in $\mathrm{CAA} .{ }^{64}$ Vascular basement membranes are specialised forms of extracellular matrix, composed of glycoproteins such as collagen IV and laminin, as well as proteoglycans such as agrin and perlecan. With increasing age and with possession of ApoE \&4 genotype, vascular basement membranes change their composition, with reduced functional efficiency. ${ }^{65} 66$ The perivascular drainage of solutes is thus impaired in ageing and with possession of ApoE $\varepsilon 4$, further adding to the burden of failure of other clearance mechanisms. ${ }^{65-68}$

Indeed, apart from intramural perivascular drainage, other mechanisms of breakdown and clearance of $A \beta$ from the brain include enzymatic breakdown, clearance via the low-density lipoprotein receptor-related protein 1 (through which most of $\mathrm{A} \beta$ is cleared), and phagocytosis by perivascular macrophages, astrocytes or microglia. ${ }^{69-72}$ Possession of ApoE $\varepsilon 4$ and ageing impact adversely on all these molecular and cellular clearance mechanisms, as well as on ATP-binding cassette transporters involved in the clearance of $\mathrm{A} \beta$. $^{73-75}$

The convective influx of CSF into the brain parenchyma has also received attention recently in relation to the clearance of $A \beta .^{76}$ When horseradish peroxidase or fluorescent $A \beta$ are injected into the CSF, they are observed in the walls of both arteries and veins at $30 \mathrm{~min}$ after injection into the CSF. ${ }^{77}$ As this process depends on optimal expression of aquaporin 4 forming channels present in the astrocyte end feet-and regulating water exchange-it has been named 'glymphatic' drainage. On a closer look using nanoparticles injected into the CSF and electron microscopy, the pial-glial basement membranes of arteries have been defined as the pathways for convective influx-or glymphatic drainage-of CSF into the cerebral parenchyma, with nanoparticles entering the brain within $5 \mathrm{~min}$ of their injection into the CSF compartment. ${ }^{79}$ It is difficult to interpret the relevance of this pathway in the context of pathogenesis of CAA, as $A \beta$ is produced within the parenchyma and drains towards the leptomeningeal surface of the brain. The interplay between intramural drainage of interstitial fluid from the parenchyma along the basement membranes surrounding smooth muscle cells and the convective influx (or glymphatic drainage) of CSF along the pial-glial basement membranes into the parenchyma thus remains to be investigated further, as it probably plays a key role in the maintenance of homeostasis of the brain and in the development of diseases of $\mathrm{A} \beta$ accumulation ${ }^{80}$ (figure 2). ${ }^{81}$

\section{Amyloid-related imaging abnormalities (ARIA): friend or foe?}

Further insights into how and why CAA may occur have come from the recent immunotherapy trials for AD. All such trials have reported 'Amyloid Related Imaging Abnormalities' (ARIA) as an unintended adverse effect; these are defined by their neuroimaging appearances as either predominantly oedematous or haemorrhagic, with the former showing vasogenic oedema and the latter developing cerebral microbleeds and cSS. ${ }^{5}$ ARIA shares a striking similarity of imaging features with the rare inflammatory variant of CAA (CAA-ri) in which spontaneously generated antibodies against vascular $A \beta$ are observed. ${ }^{53} 82$ This apparent antibody-mediated development of imaging features found in CAA raises the possibilities that CAA may either develop as a consequence of rapid removal of parenchymal $A \beta$ or trigger ARIA if already present when exposed to anti-A $\beta$ antibodies. Higher and more effective doses of $A \beta$ immunotherapy are more likely to result in ARIA, ${ }^{5384}$ and areas affected by ARIA are associated with subsequent parenchymal A $\beta$ clearance. ${ }^{58586}$ The persistence of CAA after immunisation against $A \beta 42$ suggests

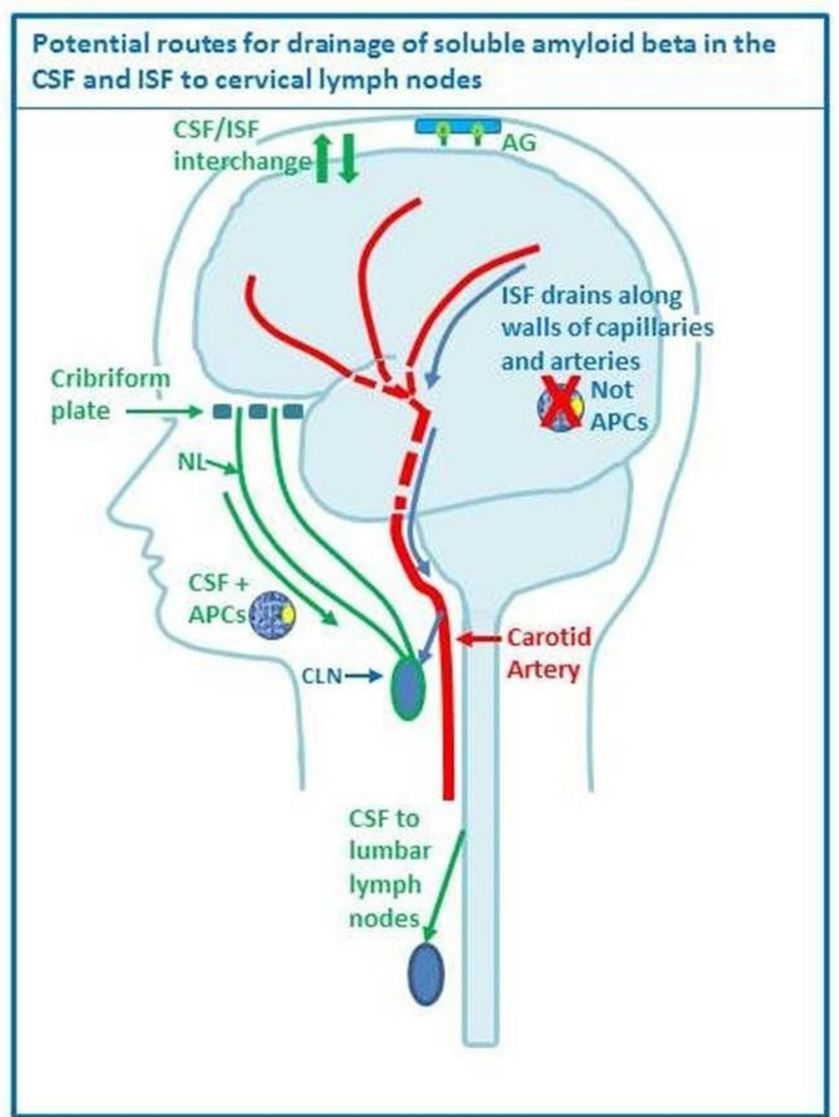

Figure 2 Drainage pathways for CSF and interstitial fluid (ISF) to cervical lymph nodes. With permission from Engelhardt et al. ${ }^{81}$ CSF and ISF drain to lymph nodes by different and distinct pathways. In humans, CSF drains into the blood of venous sinuses through well-developed arachnoid villi and granulations (AG). Lymphatic drainage of CSF occurs via nasal and dural lymphatics and along cranial and spinal nerve roots (outlined in green). Channels that pass from the subarachnoid space through the cribriform plate allow passage of CSF (green line) T cells and antigen presenting cells (APC) into nasal lymphatics (NL) and cervical lymph nodes (CLN). CSF from the lumbar subarachnoid space drains to lumbar lymph nodes. ISF from the brain parenchyma drains along basement membranes in the walls of cerebral capillaries and arteries (blue arrows) to cervical lymph nodes adjacent to the internal carotid artery just below the base of the skull. There is interchange between CSF and ISF (convective influx/glymphatic system) as CSF enters the surface of the brain alongside penetrating arteries.

that the solubilised $\mathrm{A} \beta$ from plaques becomes entrapped in the intramural periarterial drainage pathways. Recent neuropathological work found that sites of microhaemorrhage are associated with lower levels of vascular $\mathrm{A} \beta$ and less severe $\mathrm{CAA},{ }^{87}$ which again may suggest that the neuroimaging findings seen in ARIA and associated with CAA might be manifestations of attempted $\mathrm{A} \beta$ clearance. The pathophysiological process by which parenchymal $A \beta$ shifts to the vasculature may be mediated by ApoE, which is involved both in $A \beta$ transfer across the blood-brain barrier and intramural periarterial $A \beta$ transport ${ }^{85}$; this could explain the increased incidence of ARIA events in those with the ApoE $\varepsilon 4$ allele. ${ }^{88} \mathrm{~A} \beta$ immunotherapy seems to result in a shift in ApoE localisation that mirrors $A \beta$ movement, with reductions in plaque-associated ApoE and an increase in cerebrovascular expression. ${ }^{85}$ However, the clinical relevance of ARIA remains unclear, since in one recent small immunotherapy 
trial the biggest clinical improvement was seen in those with ARIA, ${ }^{83}$ suggesting that ARIA may in fact be a marker of efficacy of amyloid clearance, rather than only a deleterious side effect. Furthermore, ARIA often causes few clinical symptoms in comparison to CAA-ri. ${ }^{5}$ Thus it is possible that, while inflammatory CAA and ARIA are manifestations of active A $\beta$ clearance, sporadic CAA represents a quiescent period of disease, evidence of either previous parenchymal clearance or ongoing low-level clearance, which like many cases of ARIA may be asymptomatic. Better understanding of these processes is essential, for extending the future therapeutic use of $\mathrm{A} \beta$ immunotherapies and for understanding the mechanisms by which ICH occurs in CAA.

\section{CLINICAL IMPACT ON COGNITION \\ CAA: an increasingly recognised cause of cognitive impairment}

Recent research has expanded understanding of the relationship of CAA with cognitive impairment and highlighted effects that are separate from those due to AD pathology and macrohaemorrhage. A distinct cognitive profile of CAA has been described in living people with CAA-related syndromes, and clinical imaging studies have begun to unravel the mechanisms by which CAA impairs cognition.

Autopsy studies in community-dwelling elderly show that CAA pathology is very common in older people, with moderate to severe accumulation (present in about a third of aged individuals) associated with impaired cognition and adding to the likelihood of dementia even after controlling for the effects of $\mathrm{AD}$ and other pathologies. ${ }^{89-92} \mathrm{~A}$ detailed clinical-pathological study showed that moderate and severe CAA is also independently associated with accelerated decline in global cognition, and specifically processing speed, language skills and episodic memory. ${ }^{89}$ Most recently, two studies report on the neuropsychological profile of CAA in living people with CAA-related clinical syndromes (signifying severe CAA pathology). ${ }^{93}{ }^{94}$ Both studies excluded patients with dementia, and mostly enrolled patients after CAA-related ICH. Results were essentially concordant, with prominently impaired processing speed observed in both $^{93}{ }^{94}$ and a high prevalence of mild cognitive impairment (79\%). ${ }^{93}$ These differ from the previously mentioned autopsy studies, in which deficits in memory and language were also involved; this may be a reflection of the absence of dementia in these patient groups. The cognitive profile of CAA in these hospital-based studies differed from the community autopsy studies in that episodic memory, the sine qua non of $\mathrm{AD}$ (and mild cognitive impairment due to $\mathrm{AD}$ ), was relatively preserved. ${ }^{93}$ Finally, community-based studies have shown associations between strictly lobar microbleeds and impairments in global cognition and visuospatial executive function. ${ }^{95}{ }^{96}$ Overall, these studies show that cognitive impairment is common in people with CAA, with a profile that may be typical for vascular cognitive impairment (especially prior to developing dementia) but also includes a broader range of impairment that results in a profile that overlaps with that of other diseases.

The prospective association of CAA with risk for dementia has been further demonstrated by the findings of two longitudinal cohort studies of the risk for dementia following ICH. In these prospective cohorts, the incidence of new-onset dementia reached 29\% (95\% CI 23\% to 35\%) 4.5 years after ICH onset. ${ }^{45}$ In line with data on pre-existing dementia in patients with $\mathrm{ICH},{ }^{97}$ the risk of incident dementia among non-demented survivors of spontaneous ICH was substantial and higher in patients with lobar ICH. While ICH characteristics like size and location were likely to influence the risk of developing dementia soon after $\mathrm{ICH},{ }^{98}$ predictors of delayed dementia were strongly associated with well-known features of CAA: cSS and cerebral microbleeds. The effect of so-called 'silent' chronic lesions suggests that cognitive decline occurring after a lobar ICH is the expression of an underlying subtle small vessel-related process rather than the sole consequence of acute macro-bleeding. Therefore, to prevent cognitive decline in patients with CAA, future studies might focus on modifying and monitoring the appearance of chronic lesions such as cSS or cerebral microbleeds, rather than just trying to avoid macrohaemorrhage. The coexisting issues of haemorrhagic lesions and cognition highlight the need for closer collaborations between stroke centres and memory centres in the field of CAA.

Neuroimaging biomarker studies are beginning to identify correlates of cognitive impairment in the absence of new $\mathrm{ICH}$, implying additional mechanisms of clinically relevant brain injury in CAA. Previous studies showed that cognitive impairment in CAA was associated with higher burden WMH of presumed vascular origin ${ }^{99100}$ and brain atrophy. ${ }^{94}$ Cortical atrophy may result from CAA-related microinfarction that disconnects white matter tracts, ${ }^{101}$ suggesting that ischaemic injury contributes to cognitive impairments. ${ }^{102}$ The global burden of white matter disconnection is demonstrated by network analyses derived from diffusion-tensor MRI and graph theory methods that consider the brain to be an interconnected network. A study of 38 non-demented patients with CAA showed that global network efficiency was decreased compared with controls, and that among patients with CAA lower global network efficiency explained 34\% of the variance in processing speed and $29 \%$ of the variance in executive function, without explaining variance in memory. ${ }^{103}$ Over a mean follow-up of 1.3 years, declines in global network efficiency were detectable, particularly for posterior brain network connections, and were associated with declining executive function. ${ }^{104}$

While the associations between cognitive impairment and dementia in CAA (both with and without $\mathrm{AD}$, and in the context of ICH) are increasingly recognised, case reports suggest that CAA can present with other behavioural and psychiatric symptoms, including delirium, depression and personality change. ${ }^{105} 106$ Given the small number of reported cases, it is not clear whether CAA is causative in these cases, or simply a coincident finding. Further data on the mechanisms behind these presentations, as well as their absolute incidence, are needed.

\section{Impact and interaction of CAA in AD}

As well as contributing to cognitive impairment in patients with ICH, CAA might have an analogous independent impact in $\mathrm{AD},{ }^{89}$ which is of particular significance because $\mathrm{AD}$ and CAA frequently coexist. ${ }^{89}{ }^{90}$ Recent neuropathological work has demonstrated that CAA makes an independent cognitive contribution to $\mathrm{AD}$ dementia, even after adjusting for other age-related pathologies including $\mathrm{AD}$ pathology. ${ }^{89}$ There is evidence that patients with familial AD develop WMH up to 6 years before estimated symptom onset and that this may be a 'core feature' of familial $\mathrm{AD}^{107}$; the predominantly parietal and occipital distribution of these WMH are consistent with the distribution seen in sporadic CAA. ${ }^{107} 108$ Moreover, cortical atrophy, an imaging finding previously felt to be primarily representative of $\mathrm{AD}$ pathology, occurs in CAA even in the absence of coexistent $\mathrm{AD}$ pathology ${ }^{14}$; furthermore, those with strictly lobar microbleeds and $\mathrm{AD}$ demonstrate more grey matter atrophy and greater reductions in glucose metabolism than those without. ${ }^{109}$ 
These findings together suggest that certain clinical and radiological features that have previously been thought to exclusively represent $\mathrm{AD}$ pathology may in fact be manifestations of CAA; as a consequence, future treatment strategies for $\mathrm{AD}$ that do not consider the impact of CAA may be less efficacious in ameliorating cognitive symptoms. ${ }^{89}$

The apparent impact of CAA in those with $\mathrm{AD}$ as well as those with $\mathrm{ICH}$ raises questions about the validity of describing CAA as either predominantly 'haemorrhagic' or 'non-haemorrhagic'. Of these subtypes, the former has been associated with the ApoE $\varepsilon 2$ allele and haemorrhagic imaging markers of CAA including lobar microbleeds and cSS. ${ }^{110}$ Non-haemorrhagic CAA is associated with the presence of ApoE $\varepsilon 4^{110}$; ApoE $\varepsilon 4$ is also associated with capillary-level CAA as well as AD. ${ }^{111}$ Although it is tempting to consider the latter as a 'cognitive' CAA given these associations, evidence suggests that the situation is more complex than this. The presence of capillary CAA does not appear to be associated with cognitive decline, ${ }^{89}$ and although both ApoE $\varepsilon 2$ and ApoE $\varepsilon 4$ are associated with CAA, it is ApoE $\varepsilon 4$ that is associated with more severe CAA on neuropathological examination (as defined by Vonsattel grading). ${ }^{111} 112$ Additionally, ApoE $\varepsilon 4$ has been shown to be associated with cSS in a memory clinic population. ${ }^{41}$ Further data on the cognitive impact of ApoE $\varepsilon 2$ in CAA, in particular whether it has an effect on cognition beyond the direct damage caused by macrohaemorrhage, are needed.

\section{MANAGEMENT AND TREATMENT DILEMMAS \\ Transient focal neurological episodes}

The last 5 years have seen a continued development of our understanding and recognition of TFNEs, which are established as a common clinical feature of CAA. There is a greater appreciation of the range of symptoms with which TFNE can present, in particular 'negative' or 'transient ischaemic attack (TIA)-like' symptoms such as motor weakness, dysphasia or visual loss, which may be present in up to half of all TFNE presentations. ${ }^{113}$ Spreading onset and recurrent stereotyped attacks seem to be typical. ${ }^{113}$ There is increasing evidence that TFNE frequently occurs as a result of acute cSAH, ${ }^{113-116}$ with symptoms correlated with the site of cSAH. ${ }^{114}$ This acute cSAH has been shown to evolve (often over weeks to months ${ }^{44}$ ) by deposition of haemosiderin in superficial cortical layers as cSS, a recognised MRI marker of CAA (figure 3). ${ }^{32} 114115$ TFNE seems to be associated with focal cSS in particular. ${ }^{32}$ TFNE and cSAH both also appear to be associated with an increased risk of subsequent ICH. ${ }^{35113115}$ Rather than a direct consequence of the individual site of cSAH or cSS, the increased ICH risk could be because TFNE (via their association with cSAH and cSS) is a marker of overall leptomeningeal CAA severity; indeed, there is some evidence that future haemorrhages tend to occur in locations distant from sites of cSAH or cSS. ${ }^{114}$ The mechanism by which an acute cSAH results in TFNE remains unknown. Electroencephalography (EEG) changes, namely intermittent focal slowing, have been demonstrated in a subset of patients with $\mathrm{TFNE}^{114}$; this is of interest as similar EEG findings have been associated with the cortical spreading depression believed to underlie migraine aura. ${ }^{113} 114$ Cortical spreading depression has also been observed in patients with aneurysmal SAH, and is believed to contribute to the delayed ischaemic damage seen in these patients. ${ }^{117-119}$ However, EEG changes were only present in a small number of patients with TFNE, and it is not clear whether all TFNE presentations (for example, limb-jerking) can be explained by cortical spreading depression alone; seizure activity might play a role in some patients. Although there is

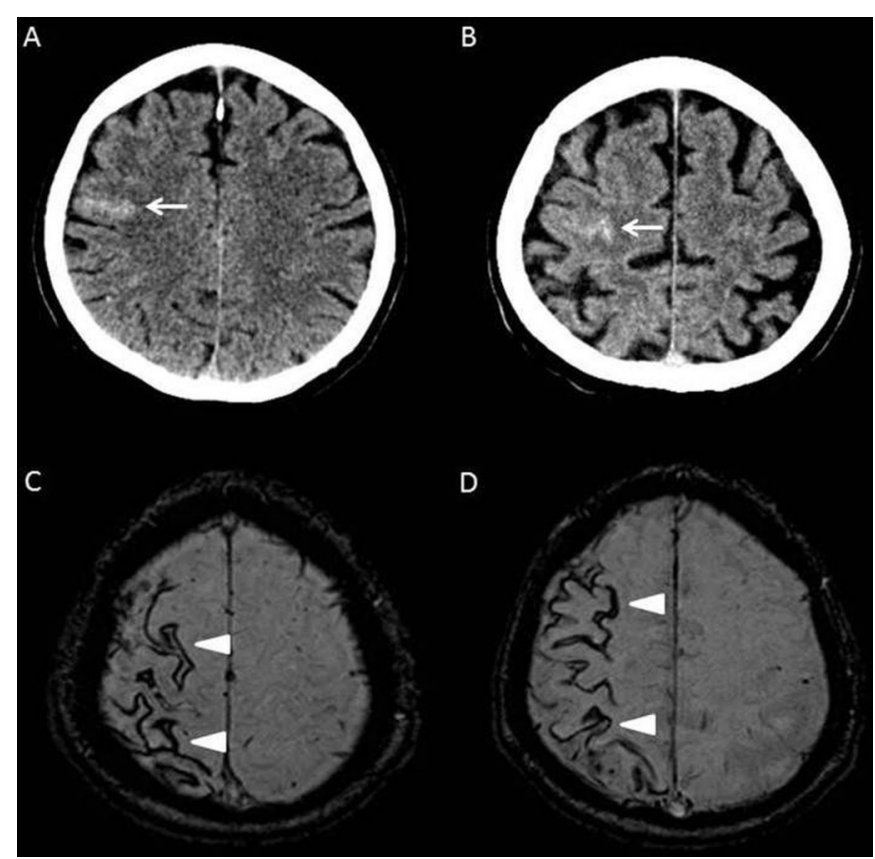

Figure 3 Imaging findings in CAA-associated TFNE. Images from a 76-year-old patient who presented with migratory left-sided sensory symptoms consistent with CAA-associated TFNE. His original CT (A) shows a hyperdense area in keeping with an acute CSAH (arrow). Three months later he had a similar episode; repeat CT (B) at this time demonstrated another acute CSAH nearby (arrow). Subsequent susceptibility weighted MRI (C and D) showed widespread disseminated CSS affecting the right hemisphere (arrowheads). CAA, cerebral amyloid angiopathy; $\mathrm{CSAH}$, convexity subarachnoid haemorrhage; CSS, cortical superficial siderosis; TFNE, transient focal neurological episodes.

increasing anecdotal data that antiepileptic and antimigraine medications (such as levetiracetam or topiramate) might reduce the frequency or severity of TFNE symptoms, ${ }^{44} 113116$ they may also remit spontaneously; controlled trial data are lacking. Recognition of CAA-related TFNE (by assessing the clinical features and performing appropriate acute neuroimaging) is critical to avoid potentially hazardous exposure to antithrombotic drugs, the standard treatment for TIAs.

\section{Management of patients with CAA with indications for antithrombotics or anticoagulants}

The thorniest dilemmas in management of patients with CAA occur when there is an unrelated indication for antithrombotic therapy. Unfortunately, this is all too common because evidencebased indications for antithrombotic therapy, such as atrial fibrillation or vaso-occlusive disease, accrue with age, just as CAA does. A study of lobar ICH survivors showed that despite an episode of life-threatening bleeding, more than 20\% had antithrombotics initiated after hospital discharge. ${ }^{120}$

With an average ICH recurrence rate in CAA of about $9 \%$ per year, ${ }^{121}$ antithrombotic strategies that increase the relative risk of ICH by more than about $50 \%$ are likely to outweigh any antithrombotic-associated reduced risk of thrombosis, even in patients with atrial fibrillation, probably causing more harm than good. Much of the early data for restarting oral anticoagulation (OAC) after an OAC-related ICH came from small hospital studies with inconclusive results. ${ }^{122-125}$ Three larger registry studies $^{126-128}$ have since demonstrated that restarting OAC after an OAC-related ICH might be of benefit, with a clear reduction 
in the risk of ischaemic stroke in all cases. With regard to recurrent ICH risk, the results are more indeterminate, with one study showing a slight risk reduction, ${ }^{126}$ another no increase in risk ${ }^{127}$ and another showing an increased risk. ${ }^{128} \mathrm{~A}$ recent meta-analysis ${ }^{129}$ including 5306 patients with anticoagulation-associated ICH from eight studies (nearly all evaluating treatment with vitamin $\mathrm{K}$ antagonists) suggested that restarting anticoagulation was associated with a lower risk of thromboembolic complications (pooled relative risk, $0.34 ; 95 \%$ CI 0.25 to $0.45 ; \mathrm{Q}=5.12$, $\mathrm{p}$ for heterogeneity $=0.28$ ), with no increased risk of recurrent ICH (although with significant heterogeneity; pooled relative risk, 1.01 ; $95 \%$ CI 0.58 to 1.77 ; $Q=24.68$, p for heterogeneity <0.001). There are also some data ${ }^{126} 130131$ that restarting anticoagulation in those with previous ICH and atrial fibrillation is associated with reduced mortality. Unfortunately, none of these observational studies distinguish between CAA-related and non-CAA-related $\mathrm{ICH}$; given the recurrent $\mathrm{ICH}$ risk is higher in those with CAA, ${ }^{17} 121132$ it is difficult to know whether the above findings are applicable to these patients. Additionally, these studies are retrospective and observational, thus lacking randomised comparisons, and may be prone to further inherent physician treatment biases about which patients with $\mathrm{ICH}$ are chosen to resume anticoagulation and which are not. Currently we suggest that it is probably not indicated to use warfarin anticoagulation in patients with CAA and a history of $\mathrm{ICH},{ }^{133}$ as warfarin reinitiation may increase the risk of recurrent $\mathrm{ICH}$ by more than fivefold in ICH survivors. ${ }^{123}$ The risk for new symptomatic haemorrhage in patients with CAA-related TFNE or cSAH is not as well defined but probably also substantial and similar to that after CAA-ICH ${ }^{35113}$; therefore, warfarin anticoagulation should probably be avoided in these patients as well.

The use of aspirin is an alternate strategy for patients with atrial fibrillation and CAA-related $\mathrm{ICH}$, but has limited evidence of efficacy for atrial fibrillation-related stroke prevention. ${ }^{134}$ The non-vitamin $\mathrm{K}$ antagonist oral anticoagulants (NOACs) have proven efficacy in atrial fibrillation-related stroke prevention but only half the risk of intracranial haemorrhage as warfarin, ${ }^{135}$ and may thus be a valuable alternative to warfarin in $\mathrm{ICH}$ survivors. In the only randomised comparison of a NOAC with aspirin, in patients considered unsuitable for warfarin, apixaban was more effective at preventing thrombotic events with no difference in rates of overall bleeding or intracranial bleeding. ${ }^{136}$ In an MRI substudy of AVERROES (Apixaban Versus Acetylsalicylic Acid [ to Prevent Stroke in Atrial Fibrillation Patients Who Have Failed or Are Unsuitable for Vitamin K Antagonist Treatment), ${ }^{137}$ the number of new microbleeds was also not different between patients assigned to apixaban versus aspirin. Finally, the use of devices to occlude the left atrial appendage could be considered in eligible patients with atrial fibrillation and history of $\mathrm{ICH},{ }^{133}$ although the optimal postimplantation antithrombotic strategy has not been defined in prospective studies in patients with CAA. Further randomised trials of anticoagulation after ICH are clearly needed and are underway. ${ }^{138}$

The risks of antithrombotic therapies in patients with incidentally discovered lobar microbleeds, possibly representing asymptomatic CAA, have been much debated ${ }^{139}$ but with little evidence on which to base decisions. In the general population, participants with lobar microbleeds have a very low annual risk of ICH (only $0.6 \%$ over mean 4.9 years of follow-up in one study ${ }^{140}$ ); however, the degree to which this risk would be increased by anticoagulation is uncertain. In patients with ischaemic stroke or TIA, cerebral microbleeds increase the risk of both future ischaemic stroke and $\mathrm{ICH}$; the absolute risk of ischaemic stroke exceeds that of $\mathrm{ICH}$, but in those with more than five microbleeds (mainly treated with antiplatelet therapy) these risks seem to be finely balanced. ${ }^{141}$ A scientific statement from the American Heart Association ${ }^{142}$ suggests that routine guideline recommended care for atrial fibrillation should be unchanged even when lobar microbleeds are present, with a preference for NOACs when anticoagulation is indicated. MRI screening prior to initiating anticoagulation is of unknown value and unlikely to be cost-effective. ${ }^{143}$ Ongoing cohort studies in patients with atrial fibrillation, ischaemic stroke and MRI, treated with OAC, will provide better prospective information on microbleeds and future ICH risk in this population. ${ }^{144} 145$

\section{Statins}

Statin use in patients with, or at risk of, ICH has been controversial since the SPARCL (Stroke Prevention by Aggressive Reduction in Cholesterol Levels) trial in 4731 patients with recent stroke (due to ischaemia or haemorrhage) or TIA found an increased risk of recurrent $\mathrm{ICH}$ in those taking high-dose atorvastatin $(55 \mathrm{ICH}$ vs 33 in the placebo group; hazard ratio, HR, 1.68, 95\% CI 1.09 to 2.58). ${ }^{146}$ In multivariable Cox regression, ICH risk was sixfold higher in those having a haemorrhagic stroke as the entry event (HR 5.65, 95\% CI 2.82 to $11.30, \mathrm{p}<0.001),{ }^{146}$ and the risk of ICH was highest in those with SVD (HR 4.99, 95\% CI 1.71 to 14.61). ${ }^{146147}$ The only other randomised study to consider the effect of statins in patients with stroke (ischaemic stroke) was the Heart Protection Study (HPS) ${ }^{148}$; a meta-analysis combining data from SPARCL and HPS found that while statin use was protective for ischaemic stroke (relative risk, RR, 0.80, 95\% CI 0.78 to 0.99 ), the risk for ICH was increased (RR $1.73,95 \% \mathrm{CI}$ 1.19 to 2.50$).{ }^{149}$

While the data for statins and $\mathrm{ICH}$ in general remain conflicting, ${ }^{150-159}$ observational data suggest that statins might be particularly associated with $\mathrm{ICH}$ in the context of CAA. A trend for association between statin use and lobar ICH for those with the ApoE $\varepsilon 4 / \varepsilon 4$ or ApoE $\varepsilon 2 / \varepsilon 4$ genotypes has been described, ${ }^{160}$ and the more recent Multicenter Study on Cerebral Haemorrhage in Italy (MUCH-Italy) study ${ }^{161}$ reported that the greatest impact of statins on future ICH risk appears to be in those with lobar haemorrhages. A decision analysis suggested that statin use in survivors of lobar ICH was associated with a reduction in quality-adjusted life years. ${ }^{162}$ There is also evidence for an association between statin use and the presence of lobar microbleeds. ${ }^{163164}$ Despite the relative paucity of data in this area and its clear limitations (most obviously the use of lobar macrohaemorrhages and microhaemorrhages as surrogate markers for CAA, and the absence of information on the influence of statin dose), recent decision analyses support caution when prescribing statins in those with CAA. ${ }^{151} 162$ Data from randomised prospective studies including ICH survivors are needed to improve our understanding of the possible risks of statin use in CAA.

\section{Immunotherapy}

June 2013 saw the start of the first therapeutic clinical trial in CAA, using the humanised monoclonal antibody ponezumab. ${ }^{165} 166$ The antibody, initially trialled in $\mathrm{AD},{ }^{166-168}$ is of interest to the CAA community given its specificity for $\mathrm{A} \beta 40$, the predominant $A \beta$ subtype in vascular deposits, ${ }^{3166}$ and its promising results in animal models. ${ }^{169}$ There were questions about which outcome markers to use for this relatively short trial, ${ }^{31}$ as well as significant safety concerns given the common occurrence of ARIA following $\mathrm{A} \beta$ immunotherapy in $\mathrm{AD} .{ }^{82}$ Given that ARIA is pathologically characterised by a shift of $A \beta$ into the vasculature and the development of imaging features consistent with 
CAA, ${ }^{5} 85$ current recommendations advise excluding patients with high microbleed counts from AD immunotherapy trials. ${ }^{170}$ However, despite worries that immunotherapy in CAA could lead to clinical deteriorations in these patients, ponezumab was well tolerated, with no ARIA-like events (Claire Leurent, Pfizer, personal communication 2017). The formal results of this study, which used occipital vascular reactivity to visual stimulation as a primary outcome measure, ${ }^{165}$ are expected later this year.

\section{WHAT'S NEXT FOR CAA?}

In the last 5 years we have seen real advances in our understanding of CAA, and there is excitement about potential future progress. The planned revision of the current Boston criteria to better reflect recent clinical and radiological discoveries is underway, and it is expected that any new criteria will address the relevance of non-haemorrhagic markers (for example, perivascular spaces in the centrum semiovale), whether the presence of deep microbleeds truly excludes a diagnosis of CAA, and whether different diagnostic criteria are needed for its haemorrhagic and cognitive subtypes. This should improve our ability to define disease presence, severity and subtypes, which might help guide clinical decision making and future trials with regard to antithrombotic, anticoagulant and statin use.

Developing treatments for CAA remains a priority; the suggestion that immunotherapy in CAA might be safe opens the road for the development of new agents with a similar mode of action. Other strategies, for example the drug (R)-1[6-[(R)-2-carboxy-pyrrolidin-1-yl]-6-oxo-hexanoyl]pyrrolidine-2-carboxylic acid (CPHPC), which targets serum amyloid P component, also hold promise. ${ }^{171}$ However, while the hope is that therapies that target vascular amyloid will be successful, there is a risk that without significant progress in our knowledge of how and why CAA develops, identifying an effective treatment will be impossible. For this reason, advances in our understanding of CAA pathophysiology and how this translates into its clinical and radiological manifestations are a crucial development needed to advance the field in future years.

Identifying an effective therapeutic approach for CAA might have a critical bearing on the treatment of $\mathrm{AD}$; given current recommendations excluding those with high microbleed counts from $\mathrm{AD}$ immunotherapy trials ${ }^{170}$ and the growing evidence that ARIA is common and possibly a marker of treatment efficacy, ${ }^{53-86}$ being able to understand and potentially treat CAA-related effects could improve safety and increase the number of patients with $\mathrm{AD}$ eligible for treatment with these agents. This raises the possibility of combination immunotherapy, with parenchymal and vascular $A \beta$ being targeted at different stages of treatment. New evidence on the impact of potentially modifiable risk factors for CAA, in particular blood pressure control, is also needed. While a subgroup analysis of PROGRESS (Perindopril Protection Against Recurrent Stroke Study) ${ }^{172}$ showed that those with probable CAA (although with limited diagnostic evaluation) had a $77 \%$ reduction in $\mathrm{ICH}$ with blood pressure lowering, there is still no guidance on specific blood pressure targets or how aggressively this should be managed in patients without macrohaemorrhage. As well as preventing recurrent $\mathrm{ICH}$, there is interest in whether blood pressure has an impact on the progression and burden of CAA, in a manner analogous to that observed in age-related deep-perforating arteriopathy, another common cerebral SVD. ${ }^{173}{ }^{174}$ Further randomised controlled trials, including the use of neuroimaging surrogate markers of CAA, will be important in determining how blood pressure control (of both level and variability) might influence the natural history of CAA. Other important areas of research include the natural history of CAA (both with and without macrohaemorrhage), identifying biomarkers for early disease and the nature and extent of cognitive impact of CAA in ICH and $\mathrm{AD}$.

\section{CONCLUSIONS}

The clinical impact of CAA is no longer disputed, and the last 5 years have witnessed a rapid increase in new knowledge in this field. Newly identified biomarkers are improving our diagnostic capability and mechanistic understanding, as well as providing practical outcome markers in clinical trials. The interaction between CAA and AD remains of great interest, both in terms of pathological and cognitive implications, and may be key to the successful use of immunotherapies in $\mathrm{AD}$ and CAA in future. The next 5 years promise new and exciting advances with the prospect of earlier, more accurate diagnosis and ultimately rational preventive and disease-modifying treatments.

\section{Author affiliations}

${ }^{1}$ Stroke Research Centre, Department of Brain Repair and Rehabilitation, UCL Institute of Neurology and the National Hospital for Neurology and Neurosurgery, London, UK

${ }^{2}$ Division of Clinical Neurosciences, Faculty of Medicine, University of Southampton, Southampton, UK

${ }^{3}$ Department of Neurology, Université de Lille, Inserm U1171, Degenerative and Vascular Cognitive Disorders, Centre Hospitalier Régional Universitaire de Lille, Lille, France

${ }^{4} J$ P Kistler Stroke Research Center, Massachusetts General Hospital, Harvard Medical School, Boston, MA, USA

${ }^{5}$ Departments of Pathology and Neurological Sciences, Rush Alzheimer's Disease Center, Rush University Medical Center, Chicago, IL, USA

${ }^{6}$ Hotchkiss Brain Institute, Department of Clinical Neurosciences, University of Calgary, Calgary, Alberta, Canada

${ }^{7}$ Department of Radiology, Leiden University Medical Center, Leiden, The Netherlands ${ }^{8}$ Radboud University Medical Center, Donders Institute for Brain, Cognition and Behaviour, Nijmegen, The Netherlands

${ }^{9}$ Departments of Neurology and Laboratory Medicine, Radboud Alzheimer Center, Nijmegen, The Netherlands

Contributors GB contributed to the design and compilation of the article, and contributed the following individual sections: Abstract, Introduction, Related developments in CAA: imaging, ARIA: friend or foe?, Impact and interaction of CAA in AD, Transient focal neurological episodes, Statins, Immunotherapy, The next five years? and Conclusions. RC contributed the section and figure on perivascular clearance, and to revision of the final manuscript. CC contributed to the section CAA: an increasingly recognised important cause of cognitive impairment, and to revision of the final manuscript. SMG contributed to the revision of the manuscript for important intellectual content. JAS contributed to the revision of the manuscript for important intellectual content. EES contributed the sections on CAA: an increasingly recognised important cause of cognitive impairment and the management of CAA patients with indications for antithrombotics or anticoagulants, as well as to the revision of the final manscript. MvB and JvdG contributed the section on Insights from hereditary cerebral haemorrhage with amyloidosis-Dutch type (HCHWA-D). MMV contributed the section on Body fluid biomarkers in sporadic CAA, and to the revision of the final manuscript. DJW contributed to the design of the article and the revision of the manuscript for important intellectual content.

Funding GB receives funding from the Rosetrees Trust. CC is a member of the Institut Universitaire de France. SMG receives funding from the National Institutes of Health. EES is supported by the Kathy Taylor Chair in Vascular Dementia of the University of Calgary. MMV was financially supported by the Internationale Stichting Alzheimer Onderzoek (projects 12506 and 14502), the American Alzheimer Association (project IIRG-10-1 73 389), and the CAVIA project (nr. 733050202; www.caviaproject.nl), which has been made possible by ZonMW. The CAVIA project is part of 'Memorabel', the research and innovation programprogramme for dementia, as part of the Dutch national 'Deltaplan for Dementia': zonmw. $\mathrm{nl} /$ dementiaresearch. The CAVIA project is a consortium of Radboudumc, LUMC, Erasmus MC, VUmc, ADX Neurosciences, Philips Healthcare, Stony Brook University and Massachusetts General Hospital. DJW receives research support from the Stroke Association, the British Heart Foundation and the Rosetrees Trust. Part of this work was undertaken at UCLH/UCL, which receives a proportion of funding from the Department of Health's National Institute for Health Research (NIHR) Biomedical Research Centres funding scheme. 
Competing interests CC was investigator in clinical trials A9951024 for Pfizer, AstraZeneca and Daiichi-Sankyo, and participated in the scientific boards for Bayer and Medtronic. Fees were paid to ADRINORD or Lille University Hospital research account (no personal funding). SMG serves on safety review committees for immunotherapy trials conducted by Biogen and Hoffman-La Roche. Massachusetts General Hospital participated in the trial of ponezumab under a Clinical Research Support Agreement with Pfizer. DJW was UK chief investigator for A9951024 (Pfizer) and has received consultancy and lecture fees from Bayer.

Provenance and peer review Commissioned; externally peer reviewed.

Open Access This is an Open Access article distributed in accordance with the terms of the Creative Commons Attribution (CC BY 4.0) license, which permits others to distribute, remix, adapt and build upon this work, for commercial use, provided the original work is properly cited. See: http://creativecommons.org/licenses/by/4.0/

(c) Article author(s) (or their employer(s) unless otherwise stated in the text of the article) 2017. All rights reserved. No commercial use is permitted unless otherwise expressly granted.

\section{REFERENCES}

1 Pantoni L. Cerebral small vessel disease: from pathogenesis and clinical characteristics to therapeutic challenges. Lancet Neurol 2010;9:689-701.

2 Smith EE, Eichler F. Cerebral amyloid angiopathy and lobar intracerebral hemorrhage. Arch Neurol 2006;63:148-51.

3 Charidimou A, Gang Q, Werring DJ. Sporadic cerebral amyloid angiopathy revisited: recent insights into pathophysiology and clinical spectrum. J Neurol Neurosurg Psychiatry 2012;83:124-37.

4 Charidimou A, Fox Z, Werring DJ, et al. Mapping the landscape of cerebral amyloid angiopathy research: an informetric analysis perspective. J Neurol Neurosurg Psychiatry 2016:87:252-9.

5 Sperling R, Salloway S, Brooks DJ, et al. Amyloid-related imaging abnormalities in patients with Alzheimer's disease treated with bapineuzumab: a retrospective analysis. Lancet Neurol 2012;11:241-9.

6 Knudsen KA, Rosand J, Karluk D, et al. Clinical diagnosis of cerebral amyloid angiopathy: validation of the Boston criteria. Neurology 2001;56:537-9.

7 Linn J, Halpin A, Demaerel P, et al. Prevalence of superficial siderosis in patients with cerebral amyloid angiopathy. Neurology 2010;74:1346-50.

8 Levy E, Carman MD, Fernandez-Madrid IJ, et al. Mutation of the Alzheimer's disease amyloid gene in hereditary cerebral hemorrhage, Dutch type. Science 1990;248:1124-6.

9 Bornebroek M, Haan J, Maat-Schieman ML, et al. Hereditary cerebral hemorrhage with amyloidosis-Dutch type (HCHWA-D): I--A review of clinical, radiologic and genetic aspects. Brain Pathol 1996:6:111-4.

10 Bornebroek M, De Jonghe C, Haan J, et al. Hereditary cerebral hemorrhage with amyloidosis Dutch type (AbetaPP 693): decreased plasma amyloid-beta 42 concentration. Neurobiol Dis 2003;14:619-23.

11 van den Boom R, Bornebroek M, Behloul F, et al. Microbleeds in hereditary cerebral hemorrhage with amyloidosis-Dutch type. Neurology 2005;64:1288-9.

12 van Rooden S, van der Grond J, van den Boom R, et al. Descriptive analysis of the Boston criteria applied to a Dutch-type cerebral amyloid angiopathy population. Stroke 2009;40:3022-7.

13 van Rooden S, van Opstal AM, Labadie G, et al. Early magnetic resonance imaging and cognitive markers of hereditary cerebral amyloid angiopathy. Stroke 2016:47:3041-4

14 Fotiadis P, van Rooden S, van der Grond J, et al. Cortical atrophy in patients with cerebral amyloid angiopathy: a case-control study. Lancet Neurol 2016;15:811-9.

15 Dumas A, Dierksen GA, Gurol ME, et al. Functional magnetic resonance imaging detection of vascular reactivity in cerebral amyloid angiopathy. Ann Neurol 2012;72:76-81.

16 van Opstal AM, van Rooden S, van Harten T, et al. Cerebrovascular function in presymptomatic and symptomatic individuals with hereditary cerebral amyloid angiopathy: a case-control study. Lancet Neurol 2017;16:115-22.

17 van Etten ES, Gurol ME, van der Grond J, et al. Recurrent hemorrhage risk and mortality in hereditary and sporadic cerebral amyloid angiopathy. Neurology 2016:87:1482-7

18 van Etten ES, Verbeek MM, van der Grond J, et al. $\beta$-Amyloid in CSF: biomarker for preclinical cerebral amyloid angiopathy. Neurology 2017;88:169-76.

19 Charidimou A, Meegahage R, Fox Z, et al. Enlarged perivascular spaces as a marker of underlying arteriopathy in intracerebral haemorrhage: a multicentre MRI cohort study. J Neurol Neurosurg Psychiat 2013;84:624-9.

20 Charidimou A, Jäger RH, Peeters A, et al. White matter perivascular spaces are related to cortical superficial siderosis in cerebral amyloid angiopathy. Stroke 2014;45:2930-5

21 Charidimou A, Jaunmuktane Z, Baron JC, et al. White matter perivascular spaces: an MRI marker in pathology-proven cerebral amyloid angiopathy? Neurology 2014:82:57-62.

$22 \mathrm{Koo} \mathrm{HW}$, Jo Kl, Yeon JY, et al. Clinical features of high-degree centrum semiovaleperivascular spaces in cerebral amyloid angiopathy. J Neurol Sci 2016;367:89-94.
23 Charidimou A, Hong YT, Jäger HR, et al. White matter perivascular spaces on magnetic resonance imaging: marker of cerebrovascular amyloid burden? Stroke 2015;46:1707-9.

24 Potter GM, Doubal FN, Jackson CA, et al. Enlarged perivascular spaces and cerebral small vessel disease. Int J Stroke 2015;10:376-81.

25 Peca S, McCreary CR, Donaldson E, et al. Neurovascular decoupling is associated with severity of cerebral amyloid angiopathy. Neurology 2013;81:1659-65.

26 Switzer AR, McCreary C, Batool S, et al. Longitudinal decrease in blood oxygenation level dependent response in cerebral amyloid angiopathy. Neuroimage Clin 2016;11:461-7.

27 Gurol ME, Dierksen G, Betensky R, et al. Predicting sites of new hemorrhage with amyloid imaging in cerebral amyloid angiopathy. Neurology 2012;79:320-6.

28 Baron JC, Farid K, Dolan E, et al. Diagnostic utility of amyloid PET in cerebral amyloid angiopathy-related symptomatic intracerebral hemorrhage. J Cereb Blood Flow Metab 2014;34:753-8

29 Farid K, Hong YT, Aigbirhio Fl, et al. Early-Phase 11C-PiB PET in amyloid angiopathyrelated symptomatic cerebral hemorrhage: potential diagnostic value? PLoS One 2015; 10:e0139926.

30 Gurol ME, Becker JA, Fotiadis P, et al. Florbetapir-PET to diagnose cerebral amyloid angiopathy: a prospective study. Neurology 2016;87:2043-9.

31 Greenberg SM, Al-Shahi Salman R, Biessels GJ, et al. Outcome markers for clinical trials in cerebral amyloid angiopathy. Lancet Neurol 2014;13:419-28.

32 Lummel N, Wollenweber FA, Demaerel P, et al. Clinical spectrum, underlying etiologies and radiological characteristics of cortical superficial siderosis. J Neurol 2015;262:1455-62.

33 Linn J, Wollenweber FA, Lummel N, et al. Superficial siderosis is a warning sign for future intracranial hemorrhage. J Neurol 2013;260:176-81.

34 Charidimou A, Peeters AP, Jäger $R$, et al. Cortical superficial siderosis and intracerebral hemorrhage risk in cerebral amyloid angiopathy. Neurology 2013;81:1666-73.

35 Wilson D, Hostettler IC, Ambler G, et al. Convexity subarachnoid haemorrhage has a high risk of intracerebral haemorrhage in suspected cerebral amyloid angiopathy. $J$ Neurol 2017:264.

36 Roongpiboonsopit D, Charidimou A, William CM, et al. Cortical superficial siderosis predicts early recurrent lobar hemorrhage. Neurology 2016;87:1863-70.

$37 \mathrm{Na} \mathrm{HK}$, Park JH, Kim JH, et al. Cortical superficial siderosis: a marker of vascular amyloid in patients with cognitive impairment. Neurology 2015;84:849-55.

38 Zonneveld HI, Goos JD, Wattjes MP, et al. Prevalence of cortical superficial siderosis in a memory clinic population. Neurology 2014;82:698-704.

39 Wollenweber FA, Buerger K, Mueller C, et al. Prevalence of cortical superficial siderosis in patients with cognitive impairment. J Neurol 2014;261:277-82.

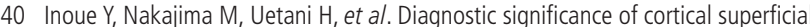
siderosis for Alzheimer Disease in patients with cognitive impairment. Am J Neuroradiol 2016:37:223-7.

41 Shams S, Martola J, Charidimou A, et al. Cortical superficial siderosis: prevalence and biomarker profile in a memory clinic population. Neurology 2016:87:1110-7.

42 Charidimou A, Ni J, Martinez-Ramirez S, et al. Cortical superficial siderosis in memory clinic patients: further evidence for underlying cerebral amyloid agiopathy. Cerebrovasc Dis 2016;41(3-4):156-62

43 Vernooij MW, Ikram MA, Hofman A, et al. Superficial siderosis in the general population. Neurology 2009;73:202-5

44 Charidimou A, Linn J, Vernooij MW, et al. Cortical superficial siderosis: detection and clinical significance in cerebral amyloid angiopathy and related conditions. Brain 2015;138(Pt 8):2126-39.

45 Moulin S, Labreuche J, Bombois S, et al. Dementia risk after spontaneous intracerebral haemorrhage: a prospective cohort study. Lancet Neurol 2016:15:820-9.

46 Martinez-Ramirez S, Romero JR, Shoamanesh A, et al. Diagnostic value of lobar microbleeds in individuals without intracerebral hemorrhage. Alzheimers Dement 2015;11:1480-8

47 Wilson D, Werring DJ. Establishing the 'meaning' of microbleeds: clinical context or lobar microbleed burden? Alzheimers Dement 2016;12:85-6.

48 Charidimou A, Martinez-Ramirez S, Reijmer YD, et al. Total magnetic resonance imaging burden of small vessel disease in cerebral amyloid angiopathy: an imaging-pathologic study of concept validation. JAMA Neurol 2016;73:994-1001.

49 Verbeek MM, Eikelenboom P, de Waal RM. Differences between the pathogenesis of senile plaques and congophilic angiopathy in Alzheimer disease. J Neuropathol Exp Neurol 1997;56:751-61.

50 Verbeek MM, Kremer BP, Rikkert MO, et al. Cerebrospinal fluid amyloid beta(40) is decreased in cerebral amyloid angiopathy. Ann Neurol 2009;66:245-9.

51 Renard D, Castelnovo G, Wacongne A, et al. Interest of CSF biomarker analysis in possible cerebral amyloid angiopathy cases defined by the modified Boston criteria. $J$ Neurol 2012:259:2429-33.

52 Renard D, Gabelle A, Hirtz C, et al. Cerebrospinal fluid Alzheimer's disease biomarkers in isolated supratentorial cortical superficial siderosis. J Alzheimers Dis 2016;54:1291-5 
53 Piazza F, Greenberg SM, Savoiardo M, et al. Anti-amyloid $\beta$ autoantibodies in cerebral amyloid angiopathy-related inflammation: implications for amyloidmodifying therapies. Ann Neurol 2013;73:449-58.

54 Renard D, Wacongne A, Ayrignac X, et al. Cerebrospinal fluid Alzheimer?s disease biomarkers in cerebral amyloid angiopathy-related inflammation. J Alzheimers Dis 2015;50:759-64.

55 Shams S, Granberg T, Martola J, et al. Cerebrospinal fluid profiles with increasing number of cerebral microbleeds in a continuum of cognitive impairment. J Cereb Blood Flow Metab 2016;36:621-8.

56 Goos JD, Kester MI, Barkhof F, et al. Patients with Alzheimer disease with multiple microbleeds: relation with cerebrospinal fluid biomarkers and cognition. Stroke 2009;40:3455-60.

57 Goos JD, Teunissen CE, Veerhuis R, et al. Microbleeds relate to altered amyloid- $\beta$ metabolism in Alzheimer's disease. Neurobiol Aging 2012;33:1011.e1-e9.

58 Kester MI, Goos JD, Teunissen CE, et al. Associations between cerebral small-vessel disease and Alzheimer disease pathology as measured by cerebrospinal fluid biomarkers. JAMA Neurol 2014;71:855-62.

59 Noguchi-Shinohara M, Komatsu J, Samuraki M, et al. Cerebral amyloid angiopathyrelated microbleeds and cerebrospinal fluid biomarkers in Alzheimer's disease. $J$ Alzheimers Dis 2017;55:905-13.

60 Gurol ME, Irizarry MC, Smith EE, et al. Plasma beta-amyloid and white matter lesions in $A D, M C l$, and cerebral amyloid angiopathy. Neurology 2006;66:23-9.

61 Hernandez-Guillamon M, Delgado P, Penalba A, et al. Plasma $\beta$-amyloid levels in cerebral amyloid angiopathy-associated hemorrhagic stroke. Neurodegener Dis 2012;10(1-4):320-3.

62 Weller RO, Subash M, Preston SD, et al. Perivascular drainage of amyloid-beta peptides from the brain and its failure in cerebral amyloid angiopathy and Alzheimer's disease. Brain Pathol 2008;18:253-66.

63 Keable A, Fenna K, Yuen HM, et al. Deposition of amyloid $\beta$ in the walls of human leptomeningeal arteries in relation to perivascular drainage pathways in cerebral amyloid angiopathy. Biochimica Biophysica Acta 2016;1862:1037-46.

64 Carare RO, Bernardes-Silva M, Newman TA, et al. Solutes, but not cells, drain from the brain parenchyma along basement membranes of capillaries and arteries: significance for cerebral amyloid angiopathy and neuroimmunology. Neuropathol App/ Neurobiol 2008;34:131-44.

65 Hawkes CA, Härtig W, Kacza J, et al. Perivascular drainage of solutes is impaired in the ageing mouse brain and in the presence of cerebral amyloid angiopathy. Acta Neuropathol 2011;121:431-43.

66 Hawkes CA, Sullivan PM, Hands S, et al. Disruption of arterial perivascular drainage of amyloid- $\beta$ from the brains of mice expressing the human APOE $\varepsilon 4$ allele. PLOS One 2012;7:e41636.

67 Ramanathan A, Nelson AR, Sagare AP, et al. Impaired vascular-mediated clearance of brain amyloid beta in Alzheimer's disease: the role, regulation and restoration of LRP1. Front Aging Neurosci 2015;7:136.

68 Hawkes CA, Gatherer M, Sharp MM, et al. Regional differences in the morphological and functional effects of aging on cerebral basement membranes and perivascular drainage of amyloid- $\beta$ from the mouse brain. Aging Cell 2013;12:224-36.

69 Rodriguez GA, Tai LM, LaDu MJ, et al. Human APOE4 increases microglia reactivity at $A \beta$ plaques in a mouse model of a $\beta$ deposition. J Neuroinflammation 2014;11:111.

70 Farris W, Schütz SG, Cirrito JR, et al. Loss of neprilysin function promotes amyloid plaque formation and causes cerebral amyloid angiopathy. Am J Pathol 2007; 171:241-51.

71 Verghese PB, Castellano JM, Garai K, et al. ApoE influences amyloid- $\beta$ (A $\beta$ ) clearance despite minimal apoE/A $\beta$ association in physiological conditions. Proc Natl Acad Sci U SA 2013:110:E1807-16.

72 Hawkes CA, McLaurin J. Selective targeting of perivascular macrophages for clearance of beta-amyloid in cerebral amyloid angiopathy. Proc Natl Acad Sci U SA 2009;106:1261-6.

73 Pahnke J, Fröhlich C, Paarmann K, et al. Cerebral ABC transporter-common mechanisms may modulate neurodegenerative diseases and depression in elderly subjects. Arch Med Res 2014:45:738-43.

74 Pahnke J, Langer 0, Krohn M. Alzheimer's and ABC transporters - new opportunities for diagnostics and treatment. Neurobiol Dis 2014;72:54-60.

75 Mounier A, Georgiev D, Nam KN, et al. Bexarotene-activated retinoid X receptors regulate neuronal differentiation and dendritic complexity. J Neurosci 2015:35:11862-76.

76 Tarasoff-Conway JM, Carare RO, Osorio RS, et al. Clearance systems in the brain implications for Alzheimer diseaser. Nat Rev Neurol 2016;12:248.

77 Rennels ML, Gregory TF, Blaumanis OR, et al. Evidence for a 'paravascular' fluid circulation in the mammalian central nervous system, provided by the rapid distribution of tracer protein throughout the brain from the subarachnoid space. Brain Res 1985:326:47-63.

78 Iliff JJ, Wang M, Liao Y, et al. A paravascular pathway facilitates CSF flow through the brain parenchyma and the clearance of interstitial solutes, including amyloid $\beta$. Sci Trans/ Med 2012;4:147ra11.

79 Morris AW, Sharp MM, Albargothy NJ, et al. Vascular basement membranes as pathways for the passage of fluid into and out of the brain. Acta Neuropathol 2016;131:725-36.
80 Bakker EN, Bacskai BJ, Arbel-Ornath M, et al. Lymphatic clearance of the brain: perivascular, paravascular and significance for neurodegenerative diseases. Cell $\mathrm{Mol}$ Neurobiol 2016;36:181-94.

81 Engelhardt B, Carare RO, Bechmann I, et al. Vascular, glial, and lymphatic immune gateways of the central nervous system. Acta Neuropathol 2016;132:317-38.

82 Piazza F. Winblad B. Amyloid-related Imaging abnormalities (ARIA) in immunotherapy trials for Alzheimer's disease: need for prognostic biomarkers? J Alzheimers Dis 2016;52:417-20.

83 Sevigny J, Chiao P, Bussière $T$, et $a$ l. The antibody aducanumab reduces $A \beta$ plaques in Alzheimer's disease. Nature 2016:537:50-6.

84 DiFrancesco JC, Longoni M, Piazza F. Anti-A $\beta$ autoantibodies in amyloid related imaging abnormalities (ARIA): candidate biomarker for immunotherapy in Alzheimer's disease and cerebral amyloid angiopathy. Front Neurol 2015;6:207.

85 Sakai K, Boche D, Carare R, et al. A $\beta$ immunotherapy for Alzheimer's disease: effects on apoE and cerebral vasculopathy. Acta Neuropathol 2014;128:777-89.

86 Boche $D$, Zotova $E$, Weller RO, et al. Consequence of $A \beta$ immunization on the vasculature of human Alzheimer's disease brain. Brain 2008;131(Pt 12):3299-310.

87 van Veluw SJ, Kuijf HJ, Charidimou A, et al. Reduced vascular amyloid burden at Microhemorrhage sites in cerebral amyloid angiopathy. Acta Neuropathol 2017;133:409-15.

88 Arrighi HM, Barakos J, Barkhof F, et al. Amyloid-related imaging abnormalitieshaemosiderin (ARIA-H) in patients with Alzheimer's disease treated with bapineuzumab: a historical, prospective secondary analysis. J Neurol Neurosurg Psychiatry 2016:87:106-12.

89 Boyle PA, Yu L, Nag S, et al. Cerebral amyloid angiopathy and cognitive outcomes in community-based older persons. Neurology 2015;85:1930-6.

90 Arvanitakis Z, Leurgans SE, Wang Z, et al. Cerebral amyloid angiopathy pathology and cognitive domains in older persons. Ann Neurol 2011:69:320-7.

91 Neuropathology Group, Medical Research Council Cognitive Function and Aging Study. Pathological correlates of late-onset dementia in a multicentre, community based population in England and Wales. Neuropathology group of the Medical Research Council Cognitive Function and Ageing Study (MRC CFAS). Lancet 2001:357:169-75.

92 Pfeifer LA, White LR, Ross GW, et al. Cerebral amyloid angiopathy and cognitive function: the HAAS autopsy study. Neurology 2002;58:1629-34.

93 Case NF, Charlton A, Zwiers A, et al. Cerebral amyloid angiopathy is associated with executive dysfunction and mild cognitive impairment. Stroke 2016;47:2010-6.

94 Xiong L, Davidsdottir S, Reijmer YD, et al. Cognitive profile and its association with neuroimaging markers of non-demented cerebral amyloid angiopathy patients in a stroke unit. J Alzheimers Dis 2016;52:171-8.

95 Gregoire SM, Smith K, Jäger HR, et al. Cerebral microbleeds and long-term cognitive outcome: longitudinal cohort study of stroke clinic patients. Cerebrovasc Dis 2012:33:430-5

96 Chung C-P, Chou K-H, Chen W-T, et al. Strictly lobar cerebral microbleeds are associated with cognitive impairment. Stroke 2016;47:2497-502.

97 Cordonnier $C$, Leys $D$, Dumont $F$, et al. What are the causes of pre-existing dementia in patients with intracerebral haemorrhages? Brain 2010;133:3281-9.

98 Biffi A, Bailey D, Anderson CD, et al. Risk factors associated with early vs delayed dementia after intracerebral hemorrhage. JAMA Neurol 2016;73:969-76.

99 Greenberg SM, Gurol ME, Rosand J, et al. Amyloid angiopathy-related vascular cognitive impairment. Stroke 2004;35:2616-9.

100 Smith EE, Gurol ME, Eng JA, et al. White matter lesions, cognition, and recurrent hemorrhage in lobar intracerebral hemorrhage. Neurology 2004;63:1606-12.

101 Auriel E, Edlow BL, Reijmer YD, et al. Microinfarct disruption of white matter structure: a longitudinal diffusion tensor analysis. Neurology 2014;83:182-8.

102 Reijmer YD, van Veluw SJ, Greenberg SM. Ischemic brain injury in cerebral amyloid angiopathy. J Cereb Blood Flow Metab 2016;36:40-54.

103 Reijmer YD, Fotiadis P, Martinez-Ramirez S, et al. Structural network alterations and neurological dysfunction in cerebral amyloid angiopathy. Brain 2015;138(Pt 1):179-88.

104 Reijmer YD, Fotiadis P, Riley GA, et al. Progression of brain network alterations in cerebral amyloid angiopathy. Stroke 2016;47:2470-5.

105 Gahr M, Nowak DA, Connemann BJ, et al. Cerebral amyloidal angiopathy - a disease with implications for neurology and psychiatry. Brain Res 2013;1519:19-30.

106 Gleason A, Hayhow B, Emmanuel J, et al. Cerebral amyloid angiopathy presenting with neuropsychiatric symptoms. Aust N Z J Psychiatry 2014:48:779-80.

107 Lee S, Viqar F, Zimmerman ME, et al. White matter hyperintensities are a core feature of alzheimer's disease: evidence from the dominantly inherited Alzheimer network. Ann Neurol 2016;79:929-39.

108 Thanprasertsuk S, Martinez-Ramirez S, Pontes-Neto OM, et al. Posterior white matter disease distribution as a predictor of amyloid angiopathy. Neurology 2014;83:794-800.

109 Samuraki M, Matsunari I, Yoshita M, et al. Cerebral amyloid angiopathy-related microbleeds correlate with glucose metabolism and brain volume in Alzheimer's disease. J Alzheimers Dis 2015:48:517-28.

110 Charidimou A, Martinez-Ramirez S, Shoamanesh A, et al. Cerebral amyloid angiopathy with and without hemorrhage: evidence for different disease phenotypes. Neurology 2015;84:1206-12. 
111 Yu L, Boyle PA, Nag S, et al. APOE and cerebral amyloid angiopathy in communitydwelling older persons. Neurobiol Aging 2015;36:2946-53.

112 Rannikmäe K, Kalaria RN, Greenberg SM, et al. APOE associations with severe CAAassociated vasculopathic changes: collaborative meta-analysis. J Neurol Neurosurg Psychiatry 2014;85:300-5.

113 Charidimou A, Peeters A, Fox Z, et al. Spectrum of transient focal neurological episodes in cerebral amyloid angiopathy: multicentre magnetic resonance imaging cohort study and meta-analysis. Stroke 2012:43:2324-30.

$114 \mathrm{Ni}$ J, Auriel E, Jindal J, et al. The characteristics of superficial siderosis and convexity subarachnoid hemorrhage and clinical relevance in suspected cerebral amyloid angiopathy. Cerebrovasc Dis 2015;39(5-6):278-86.

115 Calviere L, Cuvinciuc V, Raposo N, et al. Acute convexity subarachnoid hemorrhage related to cerebral amyloid angiopathy: clinicoradiological features and outcome. J Stroke Cerebrovasc Dis 2016;25:1009-16.

116 Apoil M, Cogez J, Dubuc L, et al. Focal cortical subarachnoid hemorrhage revealed by recurrent paresthesias: a clinico-radiological syndrome strongly associated with cerebral amyloid angiopathy. Cerebrovasc Dis 2013;36:139-44.

117 Bosche B, Graf R, Ernestus RI, et al. Recurrent spreading depolarizations after subarachnoid hemorrhage decreases oxygen availability in human cerebral cortex. Ann Neurol 2010;67:607-17.

118 Leng LZ, Fink ME, ladecola C. Spreading depolarization: a possible new culprit in the delayed cerebral ischemia of subarachnoid hemorrhage. Arch Neurol 2011;68:31-6.

119 Sánchez-Porras R, Zheng Z, Santos E, et al. The role of spreading depolarization in subarachnoid hemorrhage. Eur J Neurol 2013;20:1121-7.

120 Viswanathan A, Rakich SM, Engel C, et al. Antiplatelet use after intracerebral hemorrhage. Neurology 2006;66:206-9.

121 Poon MT, Fonville AF, Al-Shahi Salman R. Long-term prognosis after intracerebral haemorrhage: systematic review and meta-analysis. J Neurol Neurosurg Psychiatry 2014;85:660-7.

122 Claassen DO, Kazemi N, Zubkov AY, et al. Restarting anticoagulation therapy after warfarin-associated intracerebral hemorrhage. Arch Neurol 2008:65:1313-8.

123 Majeed A, Kim Y-K, Roberts RS, et al. Optimal timing of resumption of warfarin after intracranial hemorrhage. Stroke 2010;41:2860-6.

124 Yung D, Kapral MK, Asllani E, et al. Reinitiation of anticoagulation after warfarinassociated intracranial hemorrhage and mortality risk: the best practice for reinitiating anticoagulation therapy after intracranial bleeding (BRAIN) study. Can J Cardiol 2012;28:33-9.

125 Poli D, Antonucci E, Dentali F, et al. Recurrence of ICH after resumption of anticoagulation with VK antagonists: chirone study. Neurology 2014;82:1020-6.

126 Nielsen PB, Larsen TB, Skjøth F, et al. Restarting anticoagulant treatment after intracranial hemorrhage in patients with atrial fibrillation and the impact on recurrent stroke, mortality, and bleeding: a nationwide cohort study. Circulation 2015;132:517-25.

127 Pennlert J, Overholser R, Asplund K, et al. Optimal timing of anticoagulant treatment after intracerebral hemorrhage in patients with atrial fibrillation. Stroke 2017; 48:314-20

128 Nielsen PB, Larsen TB, Skjøth F, et al. Outcomes associated with resuming warfarin treatment after hemorrhagic stroke or traumatic intracranial hemorrhage in patients with atrial fibrillation. JAMA Intern Med 2017:177:563-70.

129 Murthy SB, Gupta A, Merkler AE, et al. Restarting anticoagulant therapy after intracranial hemorrhage: a systematic review and meta-Analysis. Stroke 2017:48:1594-600.

130 Chao TF, Liu CJ, Chen SJ, et al. Statins and the risk of dementia in patients with atrial fibrillation: a nationwide population-based cohort study. Int I Cardiol 2015;196:91-7.

131 Kuramatsu JB, Gerner ST, Schellinger PD, et al. Anticoagulant reversal, blood pressure levels, and anticoagulant resumption in patients with anticoagulation-related intracerebral hemorrhage. JAMA 2015;313:824-36.

132 Samarasekera N, Fonville A, Lerpiniere C, et al. Influence of intracerebral hemorrhage Location on incidence, characteristics, and outcome: population-based study. Stroke 2015;46:361-8.

133 Hemphill JC, Greenberg SM, Anderson CS, et al. Guidelines for the management of spontaneous intracerebral hemorrhage: a guideline for healthcare professionals from the American Heart Association/American Stroke Association. Stroke 2015;46:2032-60.

134 Kirchhof P, Benussi S, Kotecha D, et al. 2016 ESC guidelines for the management of atrial fibrillation developed in collaboration with EACTS. Eur I Cardiothorac Surg 2016;50:e1-88.

135 Ruff CT, Giugliano RP, Braunwald E, et al. Comparison of the efficacy and safety of new oral anticoagulants with warfarin in patients with atrial fibrillation: a metaanalysis of randomised trials. Lancet 2014;383:955-62.

136 Connolly SJ, Eikelboom J, Joyner C, et al. Apixaban in patients with atrial fibrillation. N Engl J Med 2011;364:806-17.

137 O'Donnell MJ, Eikelboom JW, Yusuf $S$, et al. Effect of apixaban on brain infarction and microbleeds: averroes-MRI assessment study. Am Heart J 2016;178:145-50.

138 van Nieuwenhuizen KM, van der Worp HB, Algra A, et al. Apixaban versus antiplatelet drugs or no antithrombotic drugs after anticoagulation-associated
intraCerebral HaEmorrhage in patients with atrial fibrillation (APACHE-AF): study protocol for a randomised controlled trial. Trials 2015;16:393.

139 Wilson D, Charidimou A, Werring DJ. Use of MRI for risk stratification in anticoagulation decision making in atrial fibrillation: promising, but more data are needed for a robust algorithm. Front Neurol 2014;5:3.

140 Akoudad S, Portegies ML, Koudstaal PJ, et al. Cerebral microbleeds are associated with an increased risk of stroke: the rotterdam study. Circulation 2015;132:509-16.

141 Wilson D, Charidimou A, Ambler G, et al. Recurrent stroke risk and cerebral microbleed burden in ischemic stroke and TIA: a meta-analysis. Neurology 2016:87:1501-10.

142 Smith EE, Saposnik G, Biessels GJ, et al. Prevention of stroke in patients with silent cerebrovascular disease: a scientific statement for healthcare professionals from the American Heart Association/American Stroke Association. Stroke 2017:48:e44-71.

143 Eckman MH, Wong LK, Soo YO, et al. Patient-specific decision-making for warfarin therapy in nonvalvular atrial fibrillation: how will screening with genetics and imaging help? Stroke 2008;39:3308-15.

144 Charidimou A, Wilson D, Shakeshaft C, et al. The clinical relevance of microbleeds in stroke study (CROMIS-2): rationale, design, and methods. Int I Stroke 2015;10:155-61.

145 Worldwide collaboration in the Microbleeds International Collaborative Network. The Lancet. Neurology 2016;15:1113-4.

146 Goldstein LB, Amarenco P, Szarek M, et al. Hemorrhagic stroke in the stroke prevention by aggressive reduction in cholesterol levels study. Neurology 2008:70(24 Pt 2):2364-70

147 Amarenco P, Bogousslavsky J, Callahan A, et al. High-dose atorvastatin after stroke or transient ischemic attack. N Engl J Med 2006;355:549-59.

148 Heart Protection Study Collaborative Group. MRC/BHF Heart Protection Study of cholesterol lowering with simvastatin in 20,536 high-risk individuals: a randomised placebo-controlled trial. Lancet 2002;360:7-22.

149 Vergouwen MDI, de Haan RJ, Vermeulen M, et al. Statin treatment and the occurrence of hemorrhagic stroke in patients with a history of cerebrovascular disease. Stroke 2008:39:497-502

150 Goldstein LB, Nederkoorn PJ. Statins and poststroke intracerebral hemorrhage: concern but increasing reassurance. Neurology 2016;86:1570-1.

151 Lauer A, Greenberg SM, Gurol ME. Statins in intracerebral hemorrhage. Curr Atheroscler Rep 2015;17:46.

152 Flint AC, Conell C, Rao VA, et al. Effect of statin use during hospitalization for intracerebral hemorrhage on mortality and discharge disposition. JAMA Neurol 2014:71:1364-71.

153 Tapia Pérez JH, Yildiz OC, Schneider T, et al. Meta-analysis of statin use for the acute therapy of spontaneous intracerebral hemorrhage. I Stroke Cerebrovasc Dis 2015:24:2521-6

154 Jung JM, Choi JY, Kim HJ, et al. Statin use in spontaneous intracerebral hemorrhage: a systematic review and meta-analysis. Int I Stroke 2015;10:10-17.

155 Winkler J, Shoup JP, Czap A, et al. Long-term improvement in outcome after intracerebral hemorrhage in patients treated with statins. I Stroke Cerebrovasc Dis 2013;22:e541-5.

156 Pan YS, Jing J, Wang YL, et al. Use of statin during hospitalization improves the outcome after intracerebral hemorrhage. CNS Neurosci Ther 2014;20:548-55.

157 Chen PS, Cheng CL, Chang YC, et al. Early statin therapy in patients with acute intracerebral hemorrhage without prior statin use. Eur J Neurol 2015;22:773-80.

158 Chen PS, Cheng CL, Kao Yang YH, et al. Impact of early statin therapy in patients with ischemic stroke or transient ischemic attack. Acta Neurol Scand 2014;129:41-8

159 Dowlatshahi D, Demchuk AM, Fang J, et al. Association of statins and statin discontinuation with poor outcome and survival after intracerebral hemorrhage. Stroke 2012;43:1518-23.

160 Woo D, Deka R, Falcone GJ, et al. Apolipoprotein E, statins, and risk of intracerebral hemorrhage. Stroke 2013;44:3013-7.

161 Pezzini A, Grassi M, lacoviello L, et al. Multicenter Study on Cerebral Haemorrhage in Italy (MUCH-Italy) Investigators. Serum cholesterol levels, HMG-CoA reductase inhibitors and the risk of intracerebral haemorrhage. The Multicenter Study on cerebral haemorrhage in Italy (MUCH-Italy). J Neurol Neurosurg Psychiatry 2016:87:924-9.

162 Westover MB, Bianchi MT, Eckman MH, et al. Statin use following intracerebral hemorrhage: a decision analysis. Arch Neurol 2011:68:573-9.

163 Haussen DC, Henninger N, Kumar S, et al. Statin use and microbleeds in patients with spontaneous intracerebral hemorrhage. Stroke 2012;43:2677-81.

164 Romero JR, Preis SR, Beiser A, et al. Risk factors, stroke prevention treatments, and prevalence of cerebral microbleeds in the Framingham Heart Study. Stroke 2014;45:1492-4

165 A phase 2, Randomized, Double Blind Placebo Controlled Trial to evaluate the safety, tolerability, Pharmacokinetics and Efficacy of Pf-04360365 (Ponezumab) In adult subjects with Probable Cerebral Amyloid Angiopathy. http://clinicaltrials.gov/show/ NCT01821118 (accessed 4 Sep 2016).

166 La Porte SL, Bollini SS, Lanz TA, et al. Structural basis of C-terminal $\beta$-amyloid peptide binding by the antibody ponezumab for the treatment of Alzheimer's disease. J Mol Biol 2012;421(4-5):525-36 
167 Burstein AH, Zhao Q, Ross J, et al. Safety and pharmacology of ponezumab (PF04360365) after a single 10-minute intravenous infusion in subjects with mild to moderate Alzheimer disease. Clin Neuropharmacol 2013;36:8-13.

168 Landen JW, Zhao Q, Cohen S, et al. Safety and pharmacology of a single intravenous dose of ponezumab in subjects with mild-to-moderate Alzheimer disease: a phase I, randomized, placebo-controlled, double-blind, dose-escalation study. Clin Neuropharmacol 2013;36:14-23.

169 Bales KR, O'Neill SM, Pozdnyakov N, et al. Passive immunotherapy targeting amyloid- $\beta$ reduces cerebral amyloid angiopathy and improves vascular reactivity. Brain 2016;139(Pt 2):563-77.

170 Sperling RA, Jack CR, Black SE, et al. Amyloid-related imaging abnormalities in amyloid-modifying therapeutic trials: recommendations from the Alzheimer's Association Research Roundtable Workgroup. Alzheimers Dement 2011;7:367-85.
171 Al-Shawi R, Tennent GA, Millar DJ, et al. Pharmacological removal of serum amyloid $P$ component from intracerebral plaques and cerebrovascular $A \beta$ amyloid deposits in vivo. Open Biol 2016;6:150202.

172 Arima H, Tzourio C, Anderson C, et al. PROGRESS Collaborative Group. Effects of perindopril-based lowering of blood pressure on intracerebral hemorrhage related to amyloid angiopathy: the progress trial. Stroke 2010;41:394-6.

173 Klarenbeek P, van Oostenbrugge RJ, Rouhl RP, et al. Ambulatory blood pressure in patients with lacunar stroke: association with total MRI burden of cerebral small vessel disease. Stroke 2013;44:2995-9.

174 Yamaguchi Y, Wada M, Sato H, et al. Impact of ambulatory blood pressure variability on cerebral small vessel disease progression and cognitive decline in community-based elderly Japanese. Am J Hypertens 2014:27:1257-67. 